\title{
Phototransduction in a Transgenic Mouse Model of Nougaret Night Blindness
}

\author{
Mustapha Moussaif, ${ }^{1}$ William W. Rubin, ${ }^{2}$ Vasily Kerov, ${ }^{1}$ Rebecca Reh, ${ }^{3}$ Desheng Chen, ${ }^{4}$ Janis Lem, ${ }^{5}$ Ching-Kang Chen, ${ }^{4}$ \\ James B. Hurley, ${ }^{3}$ Marie E. Burns, ${ }^{2}$ and Nikolai 0. Artemyev ${ }^{1}$ \\ ${ }^{1}$ Department of Physiology and Biophysics, University of Iowa College of Medicine, Iowa City, Iowa 52242, ${ }^{2}$ Center for Neuroscience and Department of \\ Psychiatry and Behavioral Sciences, University of California-Davis, Davis, California 95616, ${ }^{3}$ Department of Biochemistry, University of Washington School \\ of Medicine, Seattle, Washington 98195, ${ }^{4}$ Department of Biochemistry, Virginia Commonwealth University, Richmond, Virginia 23298, and ${ }^{5}$ Department of \\ Ophthalmology, Program in Genetics, and Tufts Center for Vision Research, Tufts University School of Medicine, Boston, Massachusetts 02111
}

The Nougaret form of dominant stationary night blindness is linked to a G38D mutation in the rod transducin- $\alpha$ subunit (T $\alpha)$. In this study, we have examined the mechanism of Nougaret night blindness using transgenic mice expressing T $\alpha$ G38D. The biochemical, electrophysiological, and vision-dependent behavioral analyses of the mouse model revealed a unique phenotype of reduced rod sensitivity, impaired activation, and slowed recovery of the phototransduction cascade. Two key deficiencies in T $\alpha \mathrm{G} 38 \mathrm{D}$ function, its poor ability to activate PDE6 (cGMP phosphodiesterase) and decreased GTPase activity, are found to be the major mechanisms altering visual signaling in transgenic mice. Despite these defects, rod-mediated sensitivity in heterozygous mice is not decreased to the extent seen in heterozygous Nougaret patients.

Key words: photoreceptor; phototransduction; transducin; retina; G-proteins; night blindness

\section{Introduction}

In the rod phototransduction cascade, transducin $(\mathrm{T})$ couples photoexcitation of rhodopsin (R) to the activation of cGMP phosphodiesterase (PDE6) (Burns and Baylor, 2001; Arshavsky et al., 2002). The GTP-bound form of the $\alpha$ subunit of transducin $(\mathrm{T} \alpha)$ binds to the $\gamma$ subunit of PDE6 (P $\gamma)$, activating the enzyme. Deactivation of this complex requires the GTPase activity of T $\alpha$, which is stimulated by the GTPase activating protein (GAP) complex RGS9-1/G $\beta_{5} /$ R9AP (He et al., 1998; Makino et al., 1999; Chen et al., 2000). In humans, mutations in key components of the cascade can cause either photoreceptor degeneration or congenital stationary night blindness (CSNB) (for review, see Dryja, 2000; Lem and Fain, 2004). One intriguing example of such a disease-linked mutation is the G38D mutation in $\mathrm{T} \alpha$, which was found in patients with a particular form of CSNB that originated in the Nougaret family (Dryja et al., 1996). Nougaret patients show an $\sim 100$-fold reduction in rod sensitivity (Sandberg et al., 1998), but the mechanism by which the mutation leads to this impairment is not known.

The functional consequences of the G38D mutation have been analyzed using a transducin-like chimeric $\mathrm{T} \alpha\left(\mathrm{T} \alpha^{*}\right)$ expressed in

Received March 28, 2006; revised May 9, 2006; accepted May 11, 2006.

This work was supported by National Institutes of Health Grants R01 EY12682, EY10843 (N.0.A.), EY14047 (M.E.B.), EY06641 (J.B.H.), and EY13811 (C.-K.C.), by the E. Matilda Ziegler Foundation for Blindness (M.E.B.), and by the Knights Templar Eye Foundation (C.-K.C.). We thank T. Dryja for the valuable discussion and Geetha Mylvaganam for repeating the sequence analysis of the entire coding region of the transducin- $\alpha$ gene in some Nougaret patients.

Correspondence should be addressed to Dr. Nikolai 0. Artemyev, Department of Physiology and Biophysics, University of lowa College of Medicine, 5-532 Bowen Science Building, 51 Newton Road, lowa City, IA 52242-1109. E-mail: nikolai-artemyev@uiowa.edu.

DOI:10.1523/JNEUROSCI.1322-06.2006

Copyright $\odot 2006$ Society for Neuroscience $\quad$ 0270-6474/06/266863-10\$15.00/0
Escherichia coli (Muradov and Artemyev, 2000). The G38D substitution did not affect the affinity of $\mathrm{T} \alpha^{\star}$ for $\mathrm{T} \beta \gamma$ nor the ability of the heterotrimer to be activated by photoexcited $\mathrm{R}\left(\mathrm{R}^{*}\right)$. However, the mutation did reduce the GTPase activity of T $\alpha^{\star}$ and its stimulation by RGS9-1. Surprisingly, the most striking impairment was a defect in the mutant effector function. T $\alpha^{\star} \mathrm{G} 38 \mathrm{D}$ failed to bind P $\gamma$ and to activate PDE6 in a reconstituted system (Muradov and Artemyev, 2000).

Based on these observations, two distinct mechanisms can contribute to the phenotype of Nougaret patients. First, the defect in GTPase activity suggested by the chimeric mutant may slow deactivation, leading to a constitutive level of T $\alpha$ and PDE activity that suppresses the dark current and reduces the amplitude of rod responses. Support for this hypothesis stems from studies of the corresponding amino acid Gly ${ }^{12}$ in $\mathrm{p} 21$ ras, which is one of the most common transforming mutations (Barbacid, 1987). A substitution of Gly ${ }^{12}$ by Val blocks the GTPase activity of p21ras and prevents its stimulation by GAPs, leading to constitutive activation of $\mathrm{p} 21 \mathrm{ras}-$ mediated pathways (Lowy and Willumsen, 1993). A second distinct mechanism is that the desensitizing effect of $\mathrm{T} \alpha \mathrm{G} 38 \mathrm{D}$ arises from its impaired ability to activate PDE6, as is the case in vitro for the chimera T $\alpha^{\star} \mathrm{G} 38 \mathrm{D}$ (Muradov and Artemyev, 2000). This mechanism would be expected to reduce the amplitude and slow the recovery kinetics of flash responses (Tsang et al., 1998). Because Nougaret CSNB is dominantly inherited (Dryja et al., 1996) and because complete loss of one T $\alpha$ allele produces little change in rod sensitivity (Calvert et al., 2000), this proposed mechanism requires a dominantnegative phenotype for $\mathrm{T} \alpha \mathrm{G} 38 \mathrm{D}$, whereby the mutant protein must block the signaling by $\mathrm{T} \alpha$ expressed from the wild-type allele. To test these two hypotheses in vivo, we have generated 
transgenic mice expressing $T \alpha G 38 \mathrm{D}$ and examined the mutant function using biochemical, electrophysiological, and visiondependent behavioral approaches.

\section{Materials and Methods}

Generation of G38D transgenic mice. All experimental procedures involving the use of mice were performed in accordance with the National Institutes of Health (NIH) guidelines and the protocol approved by the University of Iowa Animal Care and Use Committee. A pBRH T $\alpha$ transgenic construct contained the mouse T $\alpha$ genomic sequence of $\sim 5.5 \mathrm{~kb}$ (Raport et al., 1989) flanked by the $4.4 \mathrm{~kb}$ mouse rod opsin promoter fragment (Lem et al., 1991) and polyadenylation signal. The Glu-Glu (EE) monoclonal antibody epitope was introduced into $\mathrm{T} \alpha$ to quantitatively assess the level of expression of the G38D mutant (see Fig. $1 A$ ). The two substitutions required to convert the T $\alpha$ sequence ${ }^{162}$ GYVPTE ${ }^{167}$ into the epitope sequence EYMPTE, and the G38D substitution, were created using the QuickChange mutagenesis kit (Stratagene, La Jolla, CA) according to the manufacturer's protocol. The DNA fragment of 9 $\mathrm{kb}$ was released from the $\mathrm{pBRH}-\mathrm{T} \alpha \mathrm{EEG} 38 \mathrm{D}$ plasmid by restriction with NotI and gel purified. The DNA fragment was microinjected into mouse embryos and implanted into pseudopregnant females in the transgenic core facilities at the University of Iowa. Transgenic mice were identified by PCR using mouse tail DNA with a pair of primers chosen to amplify a $300 \mathrm{bp}$ fragment surrounding the junction between the T $\alpha$ and polyadenylation signal sequences. Five potential T $\alpha$ EEG38D transgenic mouse founders were generated, which were then mated to C57BL/6 mice. Three of the founders transmitted the T $\alpha$ EEG38D transgene with a Mendelian inheritance pattern, and two of the three transgenic lines expressed the T $\alpha$ mutant. To move the transgene into the hemizygous $\left(\mathrm{T} \alpha^{+/-}\right)$and knock-out $\left(\mathrm{T} \alpha^{-/-}\right)$background, one transgenic mouse line $\left(\mathrm{G} 38 \mathrm{D} / \mathrm{T} \alpha^{+/+}\right)$was selected for breeding with the $\operatorname{rod} \mathrm{T} \alpha$ knock-out mice (Calvert et al., 2000), which were homozygous for the Leu450 variant of RPE65 (Danciger et al., 2000). Control transgenic mice expressing the EE-tagged $\mathrm{T} \alpha$ in the $\mathrm{T} \alpha^{+/-}$background were generated previously (Kerov et al., 2005). The T $\alpha \mathrm{EE} / \mathrm{T} \alpha^{+/-}$mice were bred with the T $\alpha$ knock-out mice to produce $\mathrm{T} \alpha \mathrm{EE} / \mathrm{T} \alpha^{-1-}$ control animals.

Immunoblot analysis and quantification of transgene expression. Total mouse retinal homogenates were obtained by solubilization of one to two retinas in $100 \mu \mathrm{l}$ of $10 \%$ SDS-Na using brief sonication and heating. Protein concentrations were determined using the DC Protein Assay (Bio-Rad, Hercules, CA) and bovine serum albumin (BSA) dissolved in $10 \%$ SDS-Na as a standard. Typically, the total protein content of a homogenate obtained from a single mouse retina was $\sim 400-450 \mu \mathrm{g}$. Samples of retinal homogenates were subjected to SDS-PAGE in $8-12 \%$ gels, electrotransferred onto nitrocellulose membranes, and probed with the following antibodies: anti-rod $\mathrm{T} \alpha(\mathrm{K}-20)$, anti-G $\beta_{1}(\mathrm{M}-14)$, and anti$\mathrm{G} \gamma_{1}$ (P-19) (Santa Cruz Biotechnology, Santa Cruz, CA); EE monoclonal (Covance, Princeton, NJ); 1D4 monoclonal anti-rod opsin (National Cell Culture Center, Minneapolis, MN); anti-PDE6 $\alpha$ (PA1-720) and anti-PDE6 $\beta$ (PA1-722) (Affinity Bioreagents, Golden, CO); or antiRGS9. Anti-peptide RGS9-469-484 antibodies were generated in sheep by Elmira Biologicals (Iowa City, IA). The antibody-antigen complexes were detected using anti-rabbit, anti-mouse, or anti-sheep antibodies conjugated to horseradish peroxidase (Sigma, St. Louis, MO) and ECL reagent (Amersham Biosciences, Piscataway, NJ). The EE-tagged tranducin-like chimeric $\mathrm{T} \alpha^{\star}\left(\mathrm{T} \alpha^{\star} \mathrm{EE}\right)$ was constructed by PCR-directed mutagenesis similar to that described by Muradov and Artemyev (2000). E. coli-expressed and purified $\mathrm{T} \alpha^{\star} \mathrm{EE}$ with the addition of $40 \mu \mathrm{g}$ of $\mathrm{T} \alpha^{-1-}$ retinal homogenate was used as a standard. Nitrocellulose membranes were exposed to film, and integrated densities of scanned individual bands were measured with Scion Image software (version Beta 4.0.2; Scion, Frederick, MD).

Immunohistochemistry. For dark adaptation, mice were kept in the dark for at least $12 \mathrm{~h}$. All dark procedures were performed under infrared illumination using night vision goggles. For light adaptation, the pupils were dilated by applying one drop of $1 \%$ tropicamide, followed by one drop of $2.5 \%$ phenylephrine hydrochloride before exposure to a fluorescent white light (50 min, $\sim 200 \mathrm{lux}$ ). The mice were killed with $\mathrm{CO}_{2}$.
A
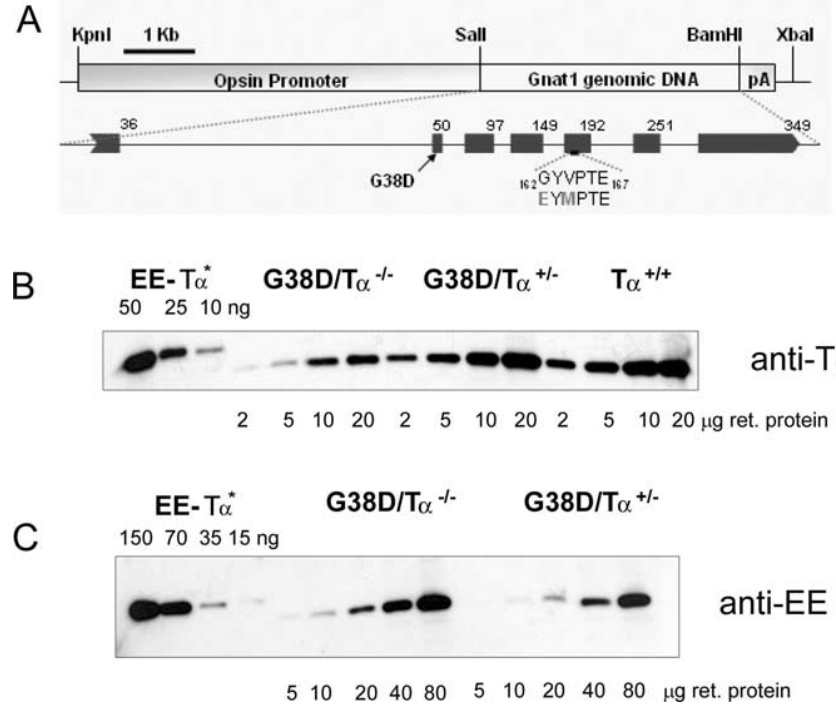

Figure 1. A, Transgenic construct used for generation of mutant $\mathrm{T} \alpha \mathrm{EE}$ and $\mathrm{T} \alpha \mathrm{EEG} 38 \mathrm{D}$ mice. $B, C$, Expression of $\mathrm{G} 38 \mathrm{D}$ in $\mathrm{G} 38 \mathrm{D} / \mathrm{T} \alpha^{-1-}$ and $\mathrm{G} 38 \mathrm{D} / \mathrm{T} \alpha^{+/-}$mice. Immunoblot analysis with anti-rod $\mathrm{T} \alpha(\mathrm{K}-20)(\boldsymbol{B})$ and anti-EE epitope $(\boldsymbol{C})$ antibodies is shown. EE-T $\alpha^{*}$-purified recombinant His6- and EE-tagged $\mathrm{T} \alpha^{*}$ are also shown. The $\mathrm{T} \alpha^{*} \mathrm{EE}$ standards were used with the addition of $40 \mu \mathrm{g}$ of $\mathrm{T} \alpha^{-I-}$ retinal homogenate. Retinas from transgenic $\mathrm{G} 38 \mathrm{D} / \mathrm{T} \alpha^{-/-}, \mathrm{G} 38 \mathrm{D} /$ $\mathrm{T} \alpha^{+/-}$, and control $\left(\mathrm{T}^{+/+}\right)$mice were homogenized and subjected to SDS-PAGE and Western blotting. ret. protein, Retinal protein.

Mouse eyeballs were enucleated, and the corneas were perforated with a 21 gauge needle and fixed in $4 \%$ formaldehyde in PBS for $1 \mathrm{~h}$ at $22^{\circ} \mathrm{C}$. After fixation, the eyeballs were cut in half, the cornea and lens were removed, and the eyecups were submersed in a $30 \%$ sucrose solution in $\mathrm{PBS}$ for $5 \mathrm{~h}$ at $4^{\circ} \mathrm{C}$. The eyecups were then embedded in tissue freezing medium (American Master ${ }^{\star}$ Tech Scientific, Lodi, CA) and frozen on dry ice. Radial sectioning $(10 \mu \mathrm{m})$ of the retina was performed using a cryomicrotome (HM 505E; Microm, Oxon, UK). Retinal cryosections were air-dried and kept at $-80^{\circ} \mathrm{C}$ until use. Before staining, sections were warmed up to $22^{\circ} \mathrm{C}$ and incubated in $0.1 \%$ Triton/PBS for $30 \mathrm{~min}$, followed by incubation with $2 \%$ normal goat serum $/ 5 \%$ BSA in PBS for 30 $\min$. Sections were then incubated with rabbit anti-rod $\mathrm{T} \alpha$ antibody TF-15 (1:200), a monoclonal anti-EE antibody (Covance), or rabbit antiarrestin antibodies (1:100) for $3 \mathrm{~h}$. After a $1 \mathrm{~h}$ incubation with goat anti-rabbit AlexaFluor 568 or goat anti-mouse AlexaFluor 488 secondary antibodies (1:1000; Invitrogen, Eugene, OR), the sections were visualized using a Zeiss (Thornwood, NY) LSM 510 confocal microscope. To evaluate mouse retina morphology, eyeballs were fixed in $2.5 \%$ gluteraldehyde in cacodylate buffer for $2 \mathrm{~h}$ at $22^{\circ} \mathrm{C}$, cut in half to remove the cornea and lens, dehydrated through a series of acetones, and embedded in Epon. Radial sections $(1 \mu \mathrm{m})$ were stained with toluidine blue and photographed through a Nikon (Tokyo, Japan) Optiphot microscope using a Spot camera (Diagnostic Instruments, Sterling Heights, MI).

Biochemical analysis of transducin function in preparations of mouse rod outer segments. Mouse rod outer segment (ROS) membranes were prepared as described previously (Tsang et al., 1998). Rhodopsin concentrations were determined using the difference in absorbance at $500 \mathrm{~nm}$ before and after photobleaching of ROS preparations solubilized in 1\% Ammonix LO. To measure light-dependent binding of GTP $\gamma \mathrm{S}$, ROSs (12 $\mu$ l) from dark-adapted G38D/T $\alpha^{+/-}, \mathrm{G} 38 \mathrm{D} / \mathrm{T} \alpha^{-1-}$, or control T $\alpha^{+/+}$ mice containing $10 \mu \mathrm{M}$ rhodopsin were mixed with $6 \mu \mathrm{l}$ of $10 \mu \mathrm{M}$ $\left[{ }^{35} \mathrm{~S}\right] \mathrm{GTP} \gamma \mathrm{S}$ under infrared illumination. After a $10 \mathrm{~s}$ incubation, the amount of bound GTP $\gamma \mathrm{S}$ was determined in a $7 \mu \mathrm{l}$ aliquot by the nitrocellulose filter binding assay (Tsang et al., 1998). The rest of the sample was bleached to determine the GTP $\gamma \mathrm{S}$ binding in the light. The singleturnover GTPase measurements were initiated by mixing photobleached ROS $(17 \mu \mathrm{l})$ containing $10 \mu \mathrm{M}$ rhodopsin with $17 \mu \mathrm{l}$ of $0.1 \mu \mathrm{M}$ $\left[\gamma-{ }^{32} \mathrm{P}\right]$ GTP. The time course of ${ }^{32} \mathrm{P}_{\mathrm{i}}$ formation was determined using 


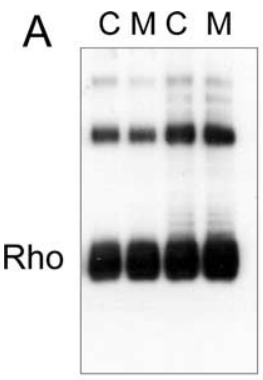

0.51 .0 $\mu \mathrm{g}$, retinal protein $\mu \mathrm{g}$, retinal protein
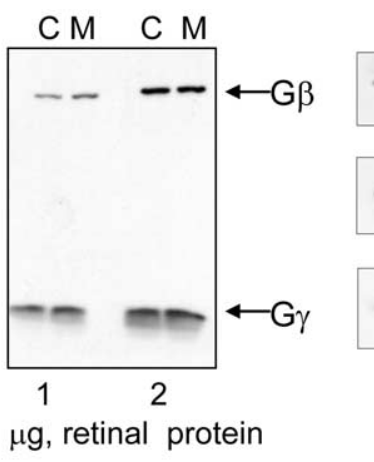

$\begin{array}{lllll}12 & 18 & 8 & 12 & 18\end{array}$ $\mu \mathrm{g}$ retinal protein

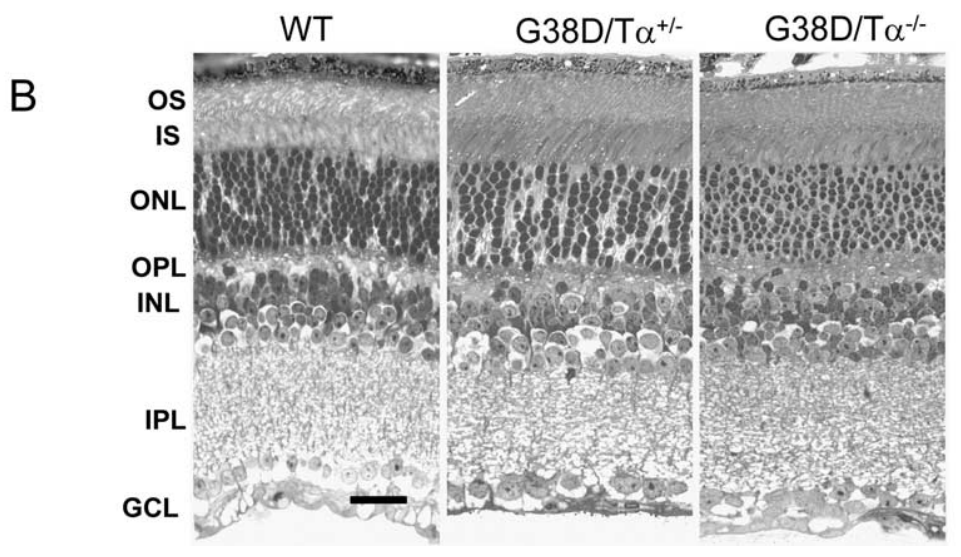

Figure 2. A, Expression of major phototransduction proteins in $\mathrm{G} 38 \mathrm{D} / \mathrm{T} \alpha^{-1-}$ mice. Retinal homogenates from control (C) and $\mathrm{G} 38 \mathrm{D} / \mathrm{T} \alpha^{-1-}$ mice (M) were analyzed by Western blotting using antibodies against rod opsin, T $\beta, \mathrm{T} \gamma, \mathrm{RGS} 9, \mathrm{PDE} 6 \alpha$, and PDE6 $\beta . B$, Retinal morphology at 5 months. Radial sections obtained from Epon-embedded mouse retinas were counterstained with toluidine blue and viewed with a Nikon Optiphot microscope, and pictures were captured using a Spot camera (Diagnostic Instruments). WT, Wild type; $0 \mathrm{NL}$, outer nuclear layer; $\mathrm{OPL}$, outer plexiform layer; INL, inner nucler layer; IPL, inner plexiform layer; $\mathrm{GCL}$, ganglion cell layer. Scale bar, $20 \mu \mathrm{m}$.

the activated charcoal procedure (Tsang et al., 1998) after the reactions were stopped with perchloric acid. The GTPase rate constants were calculated by fitting the experimental data to an exponential function: $\%$ GTP hydrolyzed $=100\left(1-e^{-k t}\right)$, where $k$ is the rate constant for GTP hydrolysis.

The interaction between the T $\alpha$ subunit and $\mathrm{P} \gamma$ was measured using a fluorescence-based assay in which $\mathrm{P} \gamma$ was labeled with 3-(bromoacetyl)7-diethyl aminocoumarin at Cys68 (P $\gamma \mathrm{BC})$ and mixed with ROS purified from transgenic or control mice. The relative change $\left(F / F_{\mathrm{o}}\right)$ in $\mathrm{P} \gamma \mathrm{BC}(10$ $\mathrm{nM}$ ) fluorescence (excitation, $445 \mathrm{~nm}$; emission, $495 \mathrm{~nm}$ ) was determined after the addition of increasing concentrations of ROS and $1 \mu \mathrm{M}$ GTP $\gamma \mathrm{S}$ (Artemyev, 1997).

To measure PDE6 activation by transducin, photobleached ROSs $\left(4 \mu \mathrm{M} \mathrm{R}^{*}\right.$ for $\mathrm{G} 38 \mathrm{D} / \mathrm{T} \alpha^{+/-}$or $\mathrm{T} \alpha^{+/+}$ROS; $10 \mu \mathrm{M} \mathrm{R} \mathrm{R}^{*}$ for G38D/ $\mathrm{T} \alpha^{-l-}$ ) were incubated with $3 \mu \mathrm{M}$ cGMP for $3 \mathrm{~min}$ to stabilize the PDE6 basal activity (Tsang et al., 1998). The reactions were started by the addition of $2 \mathrm{~mm}\left[{ }^{3} \mathrm{H}\right] \mathrm{cGMP}$ with or without $2 \mu \mathrm{M}$ GTP $\gamma$ S. cGMP hydrolysis was terminated after $10 \mathrm{~s}$ by heating the samples for $2 \mathrm{~min}$ at $100^{\circ} \mathrm{C}$. After cooling, $0.1 \mathrm{U}$ of bacterial alkaline phosphatase (Sigma) was added to each sample, followed by incubation for $20 \mathrm{~min}$ at $37^{\circ} \mathrm{C}$. Nonhydrolyzed cGMP was removed with AG1-X2 anion exchange resin (Bio-Rad), and $\left[8-{ }^{3} \mathrm{H}\right]$ guanosine was counted in a liquid scintillation counter.

Suction electrode recordings from intact rods. Mice were cared for and handled following an approved protocol from the Animal Care and Use Committee of the University of California-Davis and in compliance with NIH guidelines for the care and use of experimental animals. Before an experiment, animals were dark adapted overnight for a minimum of $12 \mathrm{~h}$. Animals were anesthetized and killed under infrared light, and the retinas were dissected and stored on ice in L-15

PDE6 $\alpha$

\section{PDE6 $\beta$}

RGS9-1 solution with $10 \mathrm{~mm}$ glucose and $0.1 \mathrm{mg} / \mathrm{ml}$ BSA (Sigma). Suction electrode recordings were performed as described previously (Krispel et al., 2003). Briefly, the retina was chopped into small pieces in a chamber containing the L-15 solution supplemented with DNase I ( $\sim 25 \mathrm{U} / \mathrm{ml}$; Amersham Biosciences). Tissue was then placed in a recording chamber perfused with bicarbonate solution, $\mathrm{pH}$ 7.4, supplemented with $10 \mathrm{~mm}$ glucose held at $35-37^{\circ} \mathrm{C}$. Individual rods were visualized under infrared light using a CCD camera (Stanford Photonics, Palo Alto, CA). The outer segment (OS) of an individual rod was gently drawn into the tip of a capillary pipette containing HEPES solution, pH 7.4. The membrane currents were recorded by a currentto-voltage converter (Axopatch 1B; Molecular Devices, Union City, CA) and lowpass filtered (8-pole Bessel; Frequency Devices, Haverhill, MA) using $30 \mathrm{~Hz}$ corner frequency. Data were digitized at $200 \mathrm{~Hz}$ using IGOR-National Instruments (Austin, TX) acquisition software (IgorPro for NIDAQ for Windows; Wavemetrics, Lake Oswego, OR) and analyzed off-line. Rods were presented with $10 \mathrm{~ms}$ flashes of $500 \mathrm{~nm}$ light. The intensity of the light was controlled by using calibrated neutral density filters.

The time course of the light-activated PDE6 activity can be described by the following equation (Pugh and Lamb, 1993):

$$
\operatorname{PDE}^{*}(t)=(1 / n)\left\{d\left[\ln \left(1-r(t) / r_{\text {max }}\right)\right] / d t\right\},
$$

where $r(t)$ is the mean flash response over time, $r_{\max }$ is the saturating response amplitude, and $n$ is the cooperativity of the cGMP-gated channel, which we assume to be 3 . The rate of rise of PDE6 activity, $\operatorname{dPDE}^{\star}(t) / d t$, was measured as the slope of a line fitted to the initial rising phase of $\operatorname{PDE}^{\star}(t)$ for a duration of at least $10 \mathrm{~ms}$. To measure $\tau_{\text {tail }}$, the tail end of the falling phase of the average flash response was fitted with a single exponential function. For responses with amplitudes that exceeded the linear range (20\% of the saturating response amplitude), the average response was first decompressed assuming exponential current saturation.

Electroretinography. Electroretinograms (ERGs) were recorded and analyzed as described previously (Kennedy et al., 2001). Mice homozygous for the RPE65Leu450 allele were selected for the paired flash recovery and dark adaptation experiments to exclude the effects of the RPE65 polymorphism on rhodopsin regeneration (Danciger et al., 2000). Mice were dark adapted overnight, anesthetized with ketamine/xylazine (140/ $0.5 \mathrm{mg} / \mathrm{kg}$ ), and maintained at $37^{\circ} \mathrm{C}$. Pupils were dilated with tropicamide and phenylephrine. Flashes were focused on the eye through a fiberoptic cable and lens. A gold ring electrode embedded in a contact lens (Bayer, 1999) was placed on one drop of 2-3\% methyl cellulose on the cornea with a reference electrode in the mouth. The unattenuated energy of the flash of white light measured at the position of the cornea was 2.9 $\mathrm{mJ} / \mathrm{cm}^{2}$. This intensity was used for the light-adapting flash for mice (see Fig. $7 C$ ), and the adapting flash was $30 \mu \mathrm{J}$ (see Fig. $7 B$ ). ERG signals were filtered between $1 \mathrm{~Hz}$ and $3 \mathrm{kHz}$ and sampled at $5 \mathrm{kHz}$.

Visual threshold measurements. We measured visual thresholds with a water maze as described previously (Hayes and Balkema, 1993; Sampath et al., 2005). Each mouse received four training trials per day for at least $10 \mathrm{~d}$ under ambient light. Times to find the platform ranged from 1 to $45 \mathrm{~s}$. The platform and black wall were rinsed and moved to a new location between trials. Testing was performed first with the brightest illumination and then decreasing one log unit in intensity per day until there was a significant increase in the time to find the platform. 


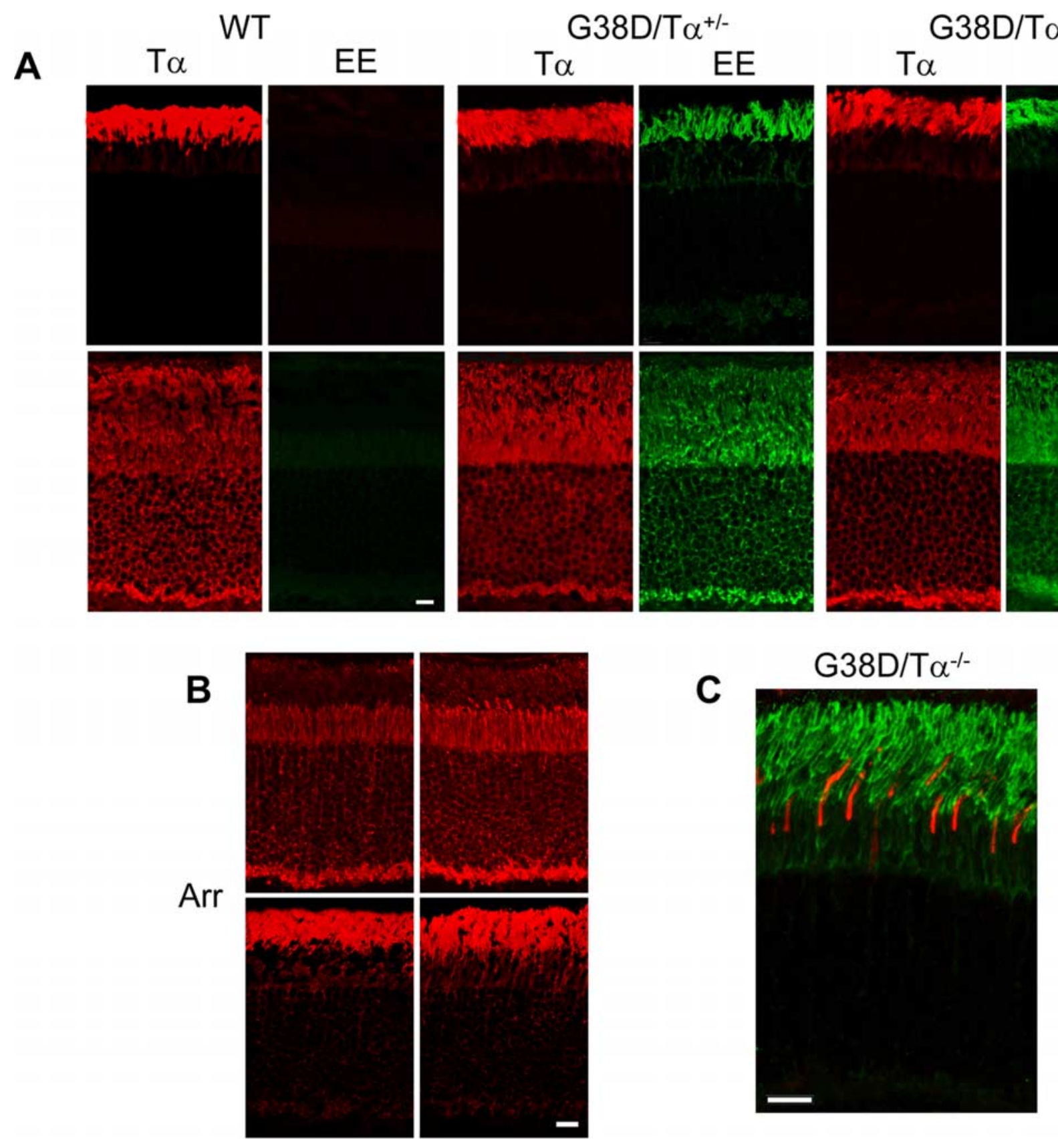

Figure 3. A, Localization and light-dependent translocation of $\mathrm{T} \alpha$ and G38D. Cryosections of the mouse retinas were obtained from dark-adapted (top row) and light-adapted (bottom row) mice (light adaptation: $50 \mathrm{~min}, \sim 200$ lux). The sections were stained with rabbit anti-rodT $\alpha$ antibody T1A or a monoclonal anti-EE antibody (Covance) and visualized with goat anti-rabbit AlexaFluor 568 and goat anti-mouse AlexaFluor 488 secondary antibodies using a Zeiss LSM 510 confocal microscope. WT, Wild type. B, Light-dependent translocation of arrestin (Arr). Cryosections of the mouse retinas from dark- and light-adapted mice (light adaptation: $50 \mathrm{~min}, \sim 200 \mathrm{lux}$ ) were stained with rabbit anti-arrestin antibody and visualized with goat anti-rabbit AlexaFluor 568 secondary antibodies using a Zeiss LSM 510 confocal microscope. C, G38D is not expressed in cone photoreceptor cells. Cryosection of mouse retina from a dark-adapted G38D/T $\alpha^{-1-}$ mouse was double stained with rabbit anti-coneT $\alpha$ antibody and a monoclonal anti-EE antibody (Covance) and visualized with goat anti-rabbit AlexaFluor 568 and goat anti-mouse AlexaFluor 488 secondary antibodies using a Zeiss LSM 510 confocal microscope. Scale bars: $A, B, 20 \mu \mathrm{m} ; C, 10 \mu \mathrm{m}$.

\section{Results}

Expression of T $\alpha$ G38D in the wild-type, $\mathrm{T}^{+/-}$, and $\mathrm{T}^{-/-}$backgrounds

To estimate the relative levels of expression of G38D and to locate the mutant and wild-type T $\alpha$ in transgenic rods, the Glu-Glu (EE) monoclonal antibody epitope was created within the loop between helices $\mathrm{E}$ and $\mathrm{F}$ of the T $\alpha$ helical domain (Fig. 1A). The EE tagging of different G-protein $\alpha$ subunits, such as Gq $\alpha$, Gs $\alpha$, and $\mathrm{Gi} \alpha$, at this location does not alter signaling activity (Wilson and Bourne, 1995; Medina et al., 1996). The EE-tagged transducin-like chimeric $\mathrm{T} \alpha^{\star}\left(\mathrm{T} \alpha^{\star} \mathrm{EE}\right)$ was similar to $\mathrm{T} \alpha^{\star}$ in all biochemical tests including coupling to $\mathrm{R}^{\star}$, GTPase activity, and interactions with RGS9 and PDE6 (Kerov et al., 2005). Two transgenic lines expressing the EE-tagged G38D mutant were established. These lines expressed G38D at similar levels ( $\sim 20 \%$ of total T $\alpha$; data not shown), and therefore only one was selected for breeding the transgene into the hemizygous $\left(\mathrm{T} \alpha^{+/-}\right)$and knockout $\left(\mathrm{T} \alpha^{-1-}\right)$ background.

The immunoblot analysis with anti-rod $\mathrm{T} \alpha$ antibody indicated that the total T $\alpha$ (G38D plus native T $\alpha$ ) level in G38D/ 
$\mathrm{T} \alpha^{+/-}$mice is similar to the $\mathrm{T} \alpha$ level in control $\mathrm{T} \alpha^{+/+}$mice ( 2.4-2.6 $\mu \mathrm{g} \mathrm{T} \alpha /$ retina) (Fig. $1 B$ ). Based on the analysis with EE antibody, expression of G38D in the T $\alpha^{+/-}$background was $\sim 25 \%$ of total T $\alpha$ (Fig. 1C). The level of G38D was higher in the T $\alpha$ knock-out background ( $0.8-0.9 \mu$ g G38D/retina; i.e., 30$35 \%$ of native $\mathrm{T} \alpha$ content in control retina), suggesting that the expression from the wild-type allele slightly suppresses expression of the transgene (Fig. 1C). The potential effect of transgene expression on levels of several key phototransduction proteins was examined by Western blot analysis with antibodies against $\mathrm{R}$, $\mathrm{T} \beta, \mathrm{T} \gamma, \mathrm{RGS} 9-1$, and PDE $6 \alpha \beta$. The levels of all these proteins were comparable in the G38D/T $\alpha^{-1-}$ and control mice (Fig. $2 A$ ). In addition, at 5 months of age, mice expressing G38D on the heterozygous $\mathrm{T} \alpha^{+/-}$and knock-out $\mathrm{T} \alpha^{-1-}$ backgrounds showed normal gross morphology of the retina with no apparent signs of retinal degeneration (Fig. $2 B$ ).

\section{Localization and light-dependent translocation of G38D in transgenic mice}

Native transducin is known to reside in the OS of dark-adapted photoreceptors. Prolonged exposure to light causes rod transducin to translocate from the OS to the inner segment (IS) (Brann and Cohen, 1987; Philp et al., 1987; Whelan and McGinnis, 1988; Sokolov et al., 2002). We compared the localization and translocation of G38D to that of wild-type T $\alpha$. Immunohistochemical analysis of mouse retinal sections using anti-rod $\mathrm{T} \alpha$ and $\mathrm{EE}$ antibodies revealed that G38D is correctly localized to the rod OS in dark-adapted G38D/T $\alpha^{+/-}$and G38D/T $\alpha^{-1-}$ mice and does not interfere with the proper OS localization of the wild-type T $\alpha$ in G38D/T $\alpha^{+/-}$rods (Fig. 3A). The patterns of light-induced translocation of $\mathrm{T} \alpha$ and G38D in G38D/T $\alpha^{+/-}, \mathrm{G} 38 \mathrm{D} / \mathrm{T} \alpha^{-/-}$, and control T $\alpha^{+/+}$mice were similar (Fig. $3 A$ ). The possibility that G38D may alter the movement of transducin to the OS during dark adaptation was also investigated. The distributions of T $\alpha$ and G38D were probed in G38D/T $\alpha^{+/-}$mice dark adapted for 4 and $10 \mathrm{~h}$ after light exposure (1000 lux, $40 \mathrm{~min}$ ). No differences were detected in the return of T $\alpha$ and G38D to the OS in control and G38D/T $\alpha^{+/-}$mice (data not shown).

Visual arrestin is another major photoreceptor protein that undergoes light-dependent translocation (Philp et al., 1987; Whelan and McGinnis, 1988). The light-induced redistribution of arrestin from the IS to the OS was normal in G38D/T $\alpha^{-1-}$ mice (Fig. $3 B$ ). In addition, because the rod opsin promoter fragment used in the transgenic construct was reported to direct expression to both rods and cones (Woodford et al., 1994), we performed double immunostaining of retinal sections from $\mathrm{G} 38 \mathrm{D} / \mathrm{T} \alpha^{-1-}$ mice with anti-EE- and cone T $\alpha$-specific antibodies. We could detect no significant expression of the G38D transgene in cones (Fig. 3C). Thus, the expression pattern and light-dependent translocation of G38D mimics that of endogenous $\mathrm{T} \alpha$.

\section{Biochemical analysis of G38D function}

Biochemical characterization of G38D mice was performed using ROS membrane fractions isolated from the G38D/T $\alpha^{+/-}, \mathrm{G} 38 \mathrm{D} /$ $\mathrm{T} \alpha^{-1-}$, and control $\mathrm{T} \alpha^{+/+}$mice. The total amount of transducin, and its gross ability to be activated by $\mathrm{R}^{\star}$, was determined by light-dependent binding of GTP $\gamma \mathrm{S}$. The basal (dark) and maximal light-dependent $\left[{ }^{35} \mathrm{~S}\right] \mathrm{GTP} \gamma \mathrm{S}$ binding levels in control and G38D/T $\alpha^{+/-}$ROSs were similar (Fig. $4 A$ ). The level of lightdependent binding of $\left[{ }^{35} \mathrm{~S}\right] \mathrm{GTP} \gamma \mathrm{S}$ to $\mathrm{G} 38 \mathrm{D} / \mathrm{T} \alpha^{-1-}$ ROS was approximately threefold lower (Fig. $4 A$ ), which is in agreement with the expression level of G38D in G38D/T $\alpha^{-1-}$ mice (see
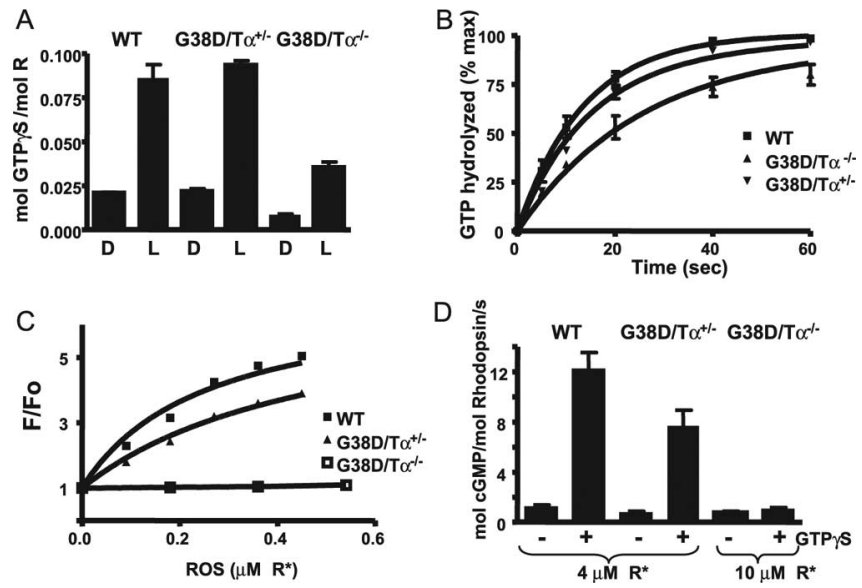

Figure 4. A, Light-dependent binding of GTP $\gamma S$ to transducin in the ROSs from control and transgenic mice. ROSs isolated from dark (D)-adapted mice (12 $\mu \mathrm{l}$ ) containing $10 \mu \mathrm{m}$ rhodopsin were mixed with $6 \mu$ of $10 \mu \mathrm{m}\left[{ }^{35} \mathrm{~S}\right] \mathrm{GTP} \gamma \mathrm{S}$ under infrared illumination. After a 10 s incubation, the amount of bound GTP $\gamma S$ was determined in a $7 \mu$ laliquot by the nitrocellulose filter binding assay. The rest of the sample was bleached to determine the GTP $\gamma$ S binding in the light (L). Error bars indicate SE $(n=3)$. $\boldsymbol{B}$, Transducin GTPase activities in the ROSs from control and transgenic mice. The single-turnover GTPase reactions were started by mixing bleached ROSs (17 $\mu$ l) containing $10 \mu \mathrm{m}$ rhodopsin with $17 \mu \mathrm{l}$ of $0.1 \mu \mathrm{m}\left[\gamma^{-}{ }^{32} \mathrm{P}\right] \mathrm{GTP}$. The time course of ${ }^{32} \mathrm{P}_{\mathrm{i}}$ formation was determined using the activated charcoal procedure after the reactions were stopped with perchloric acid. The GTPase rate constants from one-phase exponential fits for the control and G38D/T $\alpha^{-1-}$ ROSs were $0.076 \pm 0.005$ and $0.039 \pm 0.003 \mathrm{~s}^{-1}$ (mean $\pm \mathrm{SE}$; $n=3$ ). The data for G38D/T $\alpha^{+/-}$ROS were analyzed with two-phase exponential fit ( $Y_{1 \max }$ fixed at $75 \%$ and $k_{1}$ fixed at $0.076 \mathrm{~s}^{-1}$ ) yielding a $k_{2}$ of $0.032 \mathrm{~s}^{-1}$. $\max$, Maximium. C, Fluorescence $P \gamma B C$ binding assay. The relative fluorescence change $\left(F / F_{0}\right)$ of $P \gamma B C(10 \mathrm{~nm}$; excitation, $445 \mathrm{~nm}$; emission, $495 \mathrm{~nm}$ ) was determined after the addition of increasing concentrations of the ROSs from control, G38D/T $\alpha^{+/-}$, and G38D/T $\alpha^{-1-}$ mice in the presence of $1 \mu \mathrm{m} \mathrm{GTP} \gamma \mathrm{S}$. The results from one of three similar experiments are shown. $D, P D E$ activation assay. Bleached ROSs from control and G38D/T $\alpha^{+/-}$mice $\left(4 \mu \mathrm{m} \mathrm{R}^{*}\right)$ and from G38D/T $\alpha^{-/-}$mice $\left(10 \mu \mathrm{m} \mathrm{R}^{*}\right)$ were incubated with $3 \mu \mathrm{M}$ CGMP for $3 \mathrm{~min}$ to stabilize the PDE6 basal activity. The reactions were started by the addition of $2 \mathrm{~mm}\left[{ }^{3} \mathrm{H}\right] \mathrm{CGMP}$ with or without $2 \mu \mathrm{M} \mathrm{GTP} \gamma \mathrm{S}$. cGMP hydrolysis was terminated after $10 \mathrm{~s}$ by heating the samples for $2 \mathrm{~min}$ at $100^{\circ} \mathrm{C}$, and the amount of hydrolyzed cGMP was measured as described in Materials and Methods. Error bars indicate SE $(n=3)$. WT, Wild type; mol, molecular.

above). This suggests that the exchange of GDP for GTP catalyzed by $\mathrm{R}^{\star}$ is normal for the G38D protein.

The rates of GTP hydrolysis by transducin were measured under single-turnover conditions $([\mathrm{GTP}]<[\mathrm{T} \alpha \beta \gamma])$. Single exponential fits to the data yielded transducin GTP hydrolysis rates of 0.076 and $0.039 \mathrm{~s}^{-1}$ for control and G38D/T $\alpha^{-1-}$ ROS preparations, respectively (Fig. $4 B$ ). The GTP hydrolysis data for ROSs from heterozygous transgenic mice were fitted using a double exponential function weighted by the estimated expression levels for $\mathrm{G} 38 \mathrm{D} / \mathrm{T} \alpha^{+/-}$retinas ( $\sim 75 \%$ of the wild-type T $\alpha$ and $\sim 25 \%$ of the G38D mutant; see above). Holding the amplitude of the wild-type component to $75 \%$ and its rate constant to 0.076 $\mathrm{s}^{-1}$ produced a good fit $(r=0.99)$ and yielded a second rate constant of $0.032 \mathrm{~s}^{-1}$ (Fig. $4 B$ ), which is similar to that obtained in G38D/T $\alpha^{-1-}$ ROS preparations. Thus, the G38D mutant appears to exhibit the same slowed rate of GTP hydrolysis in both heterozygous and homozygous rods.

The effector function of transducin in transgenic mice was probed by both a fluorescence binding assay of the T $\alpha-\mathrm{P} \gamma$ interaction and by GTP $\gamma S$-induced activation of PDE6 in the ROS. Binding of $\mathrm{T} \alpha$ to the $\mathrm{P} \gamma$ subunit labeled at Cys68 with 3-(bromoacetyl)-7-diethyl aminocoumarin, $\mathrm{P} \gamma \mathrm{BC}$, causes a large increase in the probe fluorescence (Artemyev, 1997). The addition of increasing concentrations of the ROS from G38D/T $\alpha^{+/-}$ 
Table 1. Characteristics of flash responses of single rods

\begin{tabular}{|c|c|c|c|c|c|c|c|}
\hline & $I_{\mathrm{d}}(\mathrm{pA})$ & $I_{0}$ (photons $\left.\mu \mathrm{m}^{-2}\right)^{a}$ & $\begin{array}{l}\text { Time to peak } \\
\text { (ms) }\end{array}$ & $\begin{array}{l}\text { Elementary } \\
\text { amplitude (pA) }\end{array}$ & $\begin{array}{l}\text { Flash sensitivity } \\
\text { (pA/photons } \mu \mathrm{m}^{-2} \text { ) }\end{array}$ & $\tau_{\text {rec }}(\mathrm{ms})$ & Integration time (ms) \\
\hline Wild type & $13.2 \pm 0.6(33)$ & $48.3 \pm 2.1(25)$ & $111 \pm 6(28)$ & $0.58 \pm 0.07(18)$ & $0.186 \pm 0.018(26)$ & $200 \pm 9(26)$ & $278 \pm 22(26)$ \\
\hline $\mathrm{G} 38 \mathrm{D} / \mathrm{T} \alpha^{+/-}$ & $12.1 \pm 0.5(27)^{\# \# \# \#}$ & $77.4 \pm 6.0(22)^{* * * *, \#}$ & $109 \pm 9(22)$ & $0.37 \pm 0.06(14)^{*, \# \#}$ & $0.116 \pm 0.014(24)^{* *_{,} \# \#}$ & $207 \pm 14(20)$ & $301 \pm 33(22)$ \\
\hline $\mathrm{T} \alpha \mathrm{EE} / \mathrm{T} \alpha^{+/-}$ & $17.3 \pm 0.8(30)^{* * * *}$ & $57.7 \pm 4.7(23)$ & $115 \pm 8(24)$ & $0.79 \pm 0.10(19)$ & $0.255 \pm 0.041(22)$ & $181 \pm 24(21)$ & $270 \pm 23(22)$ \\
\hline $\mathrm{G} 38 \mathrm{D} / \mathrm{T} \alpha^{-1-}$ & $11.5 \pm 0.5(26)^{*, \# \# \#}$ & $2,296 \pm 125(26)^{* * * *, \# \# \#}$ & $192 \pm 43(25)^{*}$ & ND & 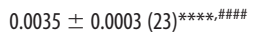 & 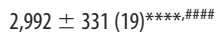 & $1,892 \pm 284(18)^{* * * *, \# \# \#}$ \\
\hline $\mathrm{T} \alpha \mathrm{EE} / \mathrm{T} \alpha^{-\prime-}$ & $16.5 \pm 0.7(31)^{* * *}$ & $59.0 \pm 3.7(20)^{*}$ & $132 \pm 11(26)$ & $0.62 \pm 0.05(19)$ & $0.203 \pm 0.019(23)$ & $209 \pm 9(24)$ & $317 \pm 18(25)$ \\
\hline
\end{tabular}

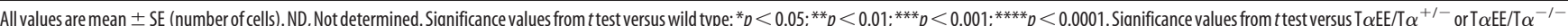

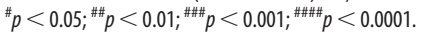

${ }^{a}$ Flash strength that elicited a half-maximal response.

mice to $\mathrm{P} \gamma \mathrm{BC}$ in the presence of $1 \mu \mathrm{M}$ GTP $\gamma \mathrm{S}$ produced a dose-dependent elevation of the $\mathrm{P} \gamma \mathrm{BC}$ fluorescence, which was $\sim 30 \%$ lower than that caused by equivalent concentrations of ROSs from control $\mathrm{T} \alpha^{+/+}$mice (Fig. 4C). In contrast, G38D/ $\mathrm{T} \alpha^{-1-}$ ROS had no effect in this assay (Fig. $4 C)$. Therefore, the smaller effect in G38D/ $\mathrm{T} \alpha^{+/-}$ROS apparently reflects only the wild-type T $\alpha$, with the G38D mutant protein showing no appreciable binding to $\mathrm{P} \gamma \mathrm{BC}$ under the assay conditions. Consistent with these results, the presence of GTP $\gamma S$ markedly stimulated cGMP hydrolysis in control ROS, produced moderately lower stimulation in $\mathrm{G} 38 \mathrm{D} / \mathrm{T} \alpha^{+/-}$ ROS, and had no significant effect in G38D/T $\alpha^{-1-}$ ROS (Fig. 4D). The lack of PDE6 activation in G38D/T $\alpha^{-1-}$ ROS was not attributable to lower G38D concentrations, because a higher ROS concentration was used to adjust the level of mutant transducin. Thus, in these assays, G38D did not bind to $\mathrm{P} \gamma$, nor did it stimulate PDE6 activity.

\section{Physiology of G38D rods}

Although the G38D mutant protein could be activated by $\mathrm{R}^{*}$ in vitro, it was not capable of activating PDE6, suggesting that G38D may not be able to mediate phototransduction in intact rods. To test this hypothesis, suction electrode recordings were made from ROSs of G38D/T $\alpha^{+/-}$, $\mathrm{G} 38 \mathrm{D} / \mathrm{T} \alpha^{-1-}$, and control mice. Control mice included both standard laboratory mice (wild-type; C57BL/6 from Charles River Laboratories, Wilmington, MA) and T $\alpha$ EE transgenic controls in the $\mathrm{T} \alpha^{+/-}$(Kerov et al., 2005) and $\mathrm{T} \alpha^{-/-}$backgrounds. The responses of $\mathrm{T} \alpha \mathrm{EE} / \mathrm{T} \alpha^{+/-}$and $\mathrm{T} \alpha \mathrm{EE} / \mathrm{T} \alpha^{-/-}$control rods were similar to wild-type rods in almost all respects (Table 1), except that $\mathrm{T} \alpha \mathrm{EE}$ control rods had significantly larger dark currents for some unknown reason. In addition, $\mathrm{T} \alpha \mathrm{EE} / \mathrm{T} \alpha^{-/-}$rods were slightly less sensitive (Table $1, I_{\mathrm{o}}$ in photons $\mu \mathrm{m}^{-2}$ ), consistent with the fact that $\mathrm{T} \alpha \mathrm{EE} / \mathrm{T} \alpha^{-/-}$mice expressed $\sim 60-65 \%$ $\mathrm{T} \alpha \mathrm{EE}$ relative to the native $\mathrm{T} \alpha$ in wild-type mice (data not shown). T $\alpha \mathrm{EE} / \mathrm{T} \alpha^{+/-}$rods, which showed normal flash sensitivity, were estimated to express $\sim 50 \%$ of $\mathrm{T} \alpha \mathrm{EE}$ and $\sim 50 \%$ of $\mathrm{T} \alpha$ (Kerov et al., 2005). Thus, the addition of the EE tag to T $\alpha$ did not alter the light responses of transgenic rods.

Quite surprisingly, rods expressing only the G38D mutant protein showed light responses, indicating that the mutation did not completely abolish the ability of transducin to activate PDE6 (Fig. 5A). However, G38D/T $\alpha^{-1-}$ rods did show a marked decrease in sensitivity to light, requiring an $\sim 40$-fold brighter flash than wild-type rods to generate a half-maximal response $\left(I_{\mathrm{o}}\right)$ (Table 1, Fig. 5B). G38D/T $\alpha^{+/-}$rods were also less sensitive, requiring, on average, a flash $\sim 40 \%$ brighter than that needed for wild-type rods (Table 1, Fig. $5 B$ ). To examine this further, we calculated the rate of change of the light-activated PDE6 activity from wild-type, G38D/T $\alpha^{+/-}$, and G38D/T $\alpha^{-/-}$rods (Fig. $5 C$ ). At all flash strengths, $\mathrm{G} 38 \mathrm{D} / \mathrm{T} \alpha^{-1-}$ rods reliably produced less light-activated PDE6 activity than wild-type rods. G38D/T $\alpha^{-1-}$ rods required $\sim 40$-fold brighter flashes to produce the same light-induced change in PDE6 activity.

In addition to reduced sensitivity, rods expressing G38D displayed impaired response recoveries. The responses of G38D/ $\mathrm{T} \alpha^{-1-}$ rods were very slow to recover at all flash strengths of light (Fig. $5 A$ ). The recovery time constant $\left(\tau_{\text {rec }}\right)$ (Table 1 ) of the smallest evoked responses was $\sim 3 \mathrm{~s}$, on average $>10$-fold slower than 

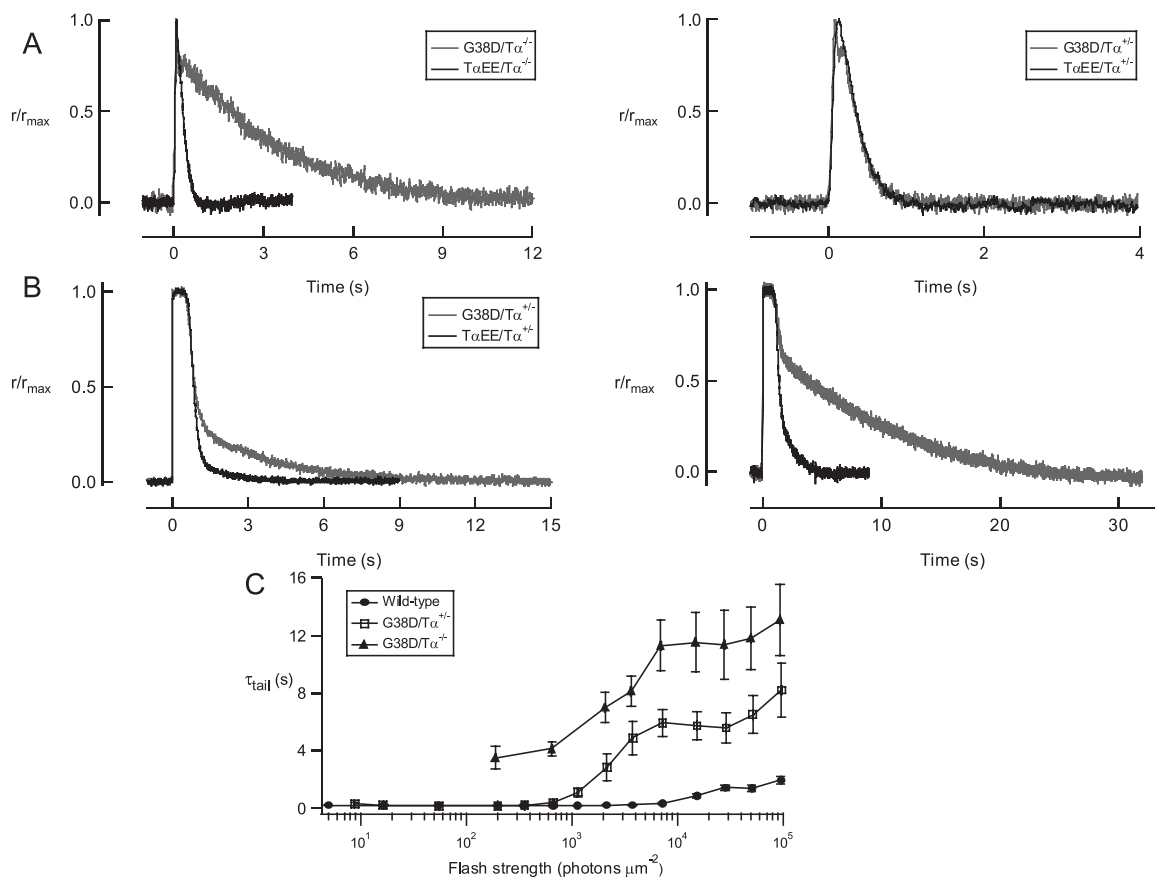

Figure 6. $\boldsymbol{A}$, Dim flash responses recover slowly in $\mathrm{G} 38 \mathrm{D} / \mathrm{T} \alpha^{-/-}$rods but not in $\mathrm{G} 38 \mathrm{D} / \mathrm{T} \alpha^{+/-}$rods. Left, G38D/ $\mathrm{T} \alpha^{-/-}$rods were much slower to recover to dim flashes of light than $\mathrm{T} \alpha \mathrm{EE} / \mathrm{T} \alpha^{-/-}$rods. Right, G38D/T $\alpha^{+/-}$and $\mathrm{T} \alpha \mathrm{EE} / \mathrm{T} \alpha^{+/-}$rods recovered along similar time courses. Dim flash responses from seven rods were averaged and normalized by the peak amplitude of the average dim flash response, which were (in picoamperes) 0.9 (G38D/T $\alpha^{-1-}$ ), $1.7\left(\mathrm{~T} \alpha \mathrm{EE} / \mathrm{T} \alpha^{-1-}\right), 1.5\left(\mathrm{G} 38 \mathrm{D} / \mathrm{T} \alpha^{+/-}\right)$, and $1.8\left(\mathrm{~T} \alpha \mathrm{EE} / \mathrm{T} \alpha^{+/-}\right)$. The average flash strength for each group (in photons $\left.\mu \mathrm{m}^{-2}\right)$ was $255\left(\mathrm{G} 38 \mathrm{D} / \mathrm{T} \alpha^{-1-}\right), 10.2\left(\mathrm{~T} \alpha \mathrm{EE} / \mathrm{T} \alpha^{-/-}\right), 12.5\left(\mathrm{G} 38 \mathrm{D} / \mathrm{T} \alpha^{+/-}\right)$, and $7.3\left(\mathrm{~T} \alpha \mathrm{EE} / \mathrm{T} \alpha^{+/-}\right)$. B, G38D/ $\mathrm{T} \alpha^{+/-}$rods recovered more slowly than control rods in response to bright flashes. Representative saturating flash responses from $\mathrm{G} 38 \mathrm{D} / \mathrm{T} \alpha^{+/-}$(gray) and $\mathrm{T} \alpha \mathrm{EE} / \mathrm{T} \alpha^{+/-}$(black) rods matched for both time in saturation and dominant time constant of recovery. From left to right, the flash strengths (in photons $\mu \mathrm{m}^{-2}$ ) used to elicit the responses were 2161 and $7322\left(\mathrm{G} 38 \mathrm{D} / \mathrm{T} \alpha^{+/-}\right)$and 2048 and $6940\left(\mathrm{~T} \alpha \mathrm{EE} / \mathrm{T} \alpha^{+/-}\right)$. Note the slow "tail" of recovery of the $\mathrm{G} 38 \mathrm{D} / \mathrm{T} \alpha^{+/-}$ responses. The maximal responses for these two cells were $13.1 \mathrm{pA}\left(\mathrm{G} 38 \mathrm{D} / \mathrm{T} \alpha^{+/-}\right)$and $12.3 \mathrm{pA}\left(\mathrm{T} \alpha \mathrm{EE} / \mathrm{T} \alpha^{+/-}\right)$C, The final falling phase of recovery from wild-type, $\mathrm{G} 38 \mathrm{D} / \mathrm{T} \alpha^{+/-}$, and $\mathrm{G} 38 \mathrm{D} / \mathrm{T} \alpha^{-1-}$ responses was fitted with a single exponential $\left(\tau_{\text {tail }}\right)$. At dim flash strengths, recovery of responses from $\mathrm{G} 38 \mathrm{D} / \mathrm{T} \alpha^{+/-}$rods was indistinguishable from that of wild-type rods. As the flash strength increased, the $\tau_{\text {tail }}$ increased until, at the brightest flash strengths, it was very similar to $\mathrm{G} 38 \mathrm{D} / \mathrm{T} \alpha^{-1-}$ rods.

that of control responses (Fig. 6A). As the flash strength increased, so did the recovery time constant $\left(\tau_{\text {tail }}\right)$ (Fig. $6 C$ ), probably because the very bright flashes depleted factors required for deactivating the cascade. In the heterozygous rods, recovery was slow only in response to bright flashes of light. The kinetics of the dim flash response of $\mathrm{G} 38 \mathrm{D} / \mathrm{T} \alpha^{+/-}$rods were similar in all respects to those of control rods (Table 1, Fig. 6A), suggesting that G38D did not significantly contribute to or interfere with the signaling of native $\mathrm{T} \alpha$ under these conditions. As the flash strength increased, however, striking differences between G38D/ $\mathrm{T} \alpha^{+-}$and control responses became apparent. Brighter, saturating flashes produced responses that were initially normal but developed a very slow final phase of recovery (Fig. $6 B, C$ ). Taking into account the properties of G38D in vitro (the reduced GTPase activity and the greatly impaired ability to activate PDE6), we interpret the results from single-cell recordings to indicate that light-activated G38D molecules activated PDE6 so poorly that their effect was not discernible until a great number of them were activated by a bright flash. Once activated, the G38D/PDE6 complexes took a longer than normal time to inactivate, thereby prolonging response recovery.

It has been postulated that impaired GTPase activity may lead to desensitization in Nougaret patients because of constitutive activity of the phototransduction cascade (Sandberg et al., 1998). If G38DT $\alpha$ were a constitutively active mutation, one would expect a decrease in the dark current (measured by the maximal response amplitudes) of G38D-expressing rods. However, the dark currents of $\mathrm{G} 38 \mathrm{D} / \mathrm{T} \alpha^{+/-}$rods were not significantly different than wild-type rods (Table $1, I_{\mathrm{d}}$ ). In addition, although the average $I_{\mathrm{d}}$ value for $\mathrm{G} 38 \mathrm{D} / \mathrm{T} \alpha^{-1-}$ rods was lower than the wild-type value ( $p=0.04$ ) (Table 1$)$, the effect was modest and may be attributable to the fact that the saturating flashes used to calculate $I_{\mathrm{d}}$ were usually given toward the end of a recording session because of the very long times required to obtain full response recovery. Thus, we found no evidence for rod desensitization by constitutive activity. In $\mathrm{G} 38 \mathrm{D} / \mathrm{T} \alpha^{+/-}$rods, the small reduction in sensitivity can best be explained by the reduced ability of G38D to activate PDE6. G38D does not seem to exert a dominant-negative effect on wild-type transducin.

\section{ERG analysis of recovery and dark adaptation of G38D mutant mice}

To support our single-cell analysis, we performed ERG analysis on $\mathrm{G} 38 \mathrm{D} / \mathrm{T} \alpha^{+/-}$, $\mathrm{G} 38 \mathrm{D} / \mathrm{T} \alpha^{-1-}$, and wild-type mice (Kennedy et al., 2001). The ERG responses to dim flashes confirmed that the rod sensitivity in dark-adapted $\mathrm{G} 38 \mathrm{D} / \mathrm{T} \alpha^{+/-}$ mice is near normal but is greatly reduced in $\mathrm{G} 38 \mathrm{D} / \mathrm{T} \alpha^{-1-}$ mice (Fig. $7 A$ ). Paired flash analysis was then used to measure recovery of the rod photocurrent after a bright conditioning flash that caused $\sim 2 \times$ $10^{5}$ photoisomerisations per rod. The rate of recovery of the ERG a-wave was markedly slower for G38D/ $\mathrm{T} \alpha^{+/-}$mice compared with wild-type mice (Fig. 7B), in agreement with the light responses recorded from individual G38D/ $\mathrm{T} \alpha^{+/-}$rods. Paired flash analysis was also used to measure recovery of the rod photocurrent after a much brighter conditioning flash, bleaching $10-20 \%$ of rhodopsin in the retina. The rate of recovery from the very bright flash for wild-type mice ( 0.085 per minute) was almost three times faster than that for G38D/T $\alpha^{+/-}$mice (Fig. $7 C$ ). Because recovery of the a-wave after such an intense conditioning flash represents a measure of dark adaptation (Kennedy et al., 2001), these results indicate that slow inactivation of G38D limits the kinetics of dark adaptation after an intense flash.

To examine dark adaptation in mutant mice after continuous illumination, we exposed mice to 200 lux of white light for $50 \mathrm{~min}$ and allowed them to dark-adapt again for 35 or $60 \mathrm{~min}$. To avoid potential effects of anesthesia on dark adaptation, the mice were not anesthetized until $5 \mathrm{~min}$ before the ERGs were recorded. The ERG responses from G38D/T $\alpha^{+/-}$and wild-type mice had similar time courses of dark adaptation (Fig. 8). Apparently, the rate of dark adaptation in mice under these experimental conditions is so slow that differences in the rates of transducin inactivation have a negligible effect. 


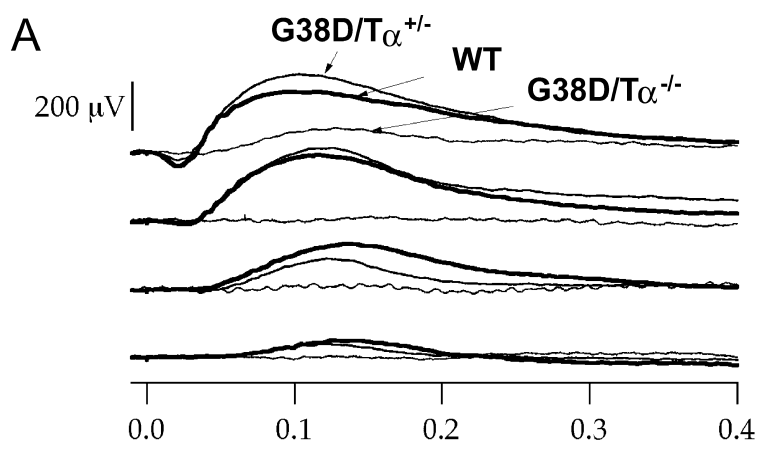

B
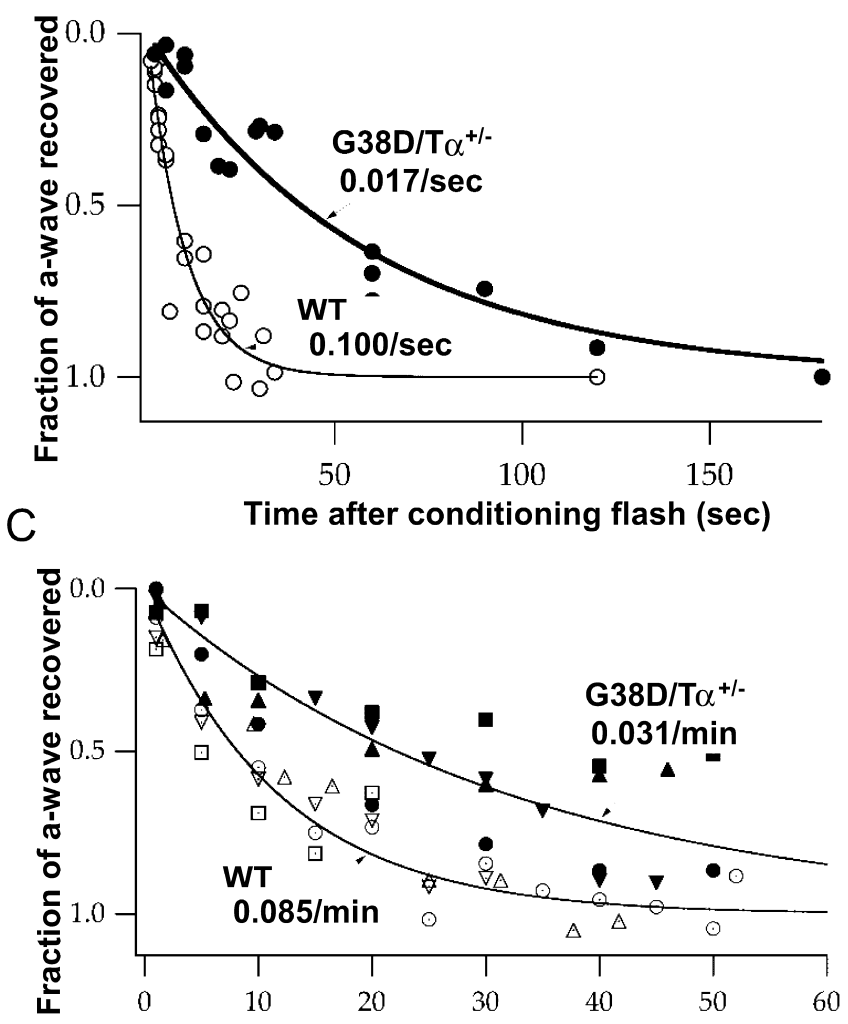

Time after conditioning flash $(\mathrm{min})$

Figure 7. $\quad A$, Dim flash ERG responses. Mice were dark adapted overnight, and ERGs were recorded. Thin curve, G38D/T $\alpha^{-1-}$ mice; medium curve, $\mathrm{G} 38 \mathrm{D} / \mathrm{T} \alpha^{+/-}$mice; bold curve, wild-type mice. Flashes were estimated to produce between $4 \times 10^{-1}$ (dimmest) to $4 \times 10^{2}$ (brightest) photoisomerisations per rod. $\boldsymbol{B}$, Recovery after a bright flash. Paired flash analysis was used to measure recovery of the rod photocurrent after a bright conditioning flash that caused $\sim 2 \times 10^{5}$ photoisomerisations per rod. The probe flash was identical to the conditioning flash. C, Recovery after a very bright flash. Paired flash analysis was used to measure recovery of the rod photocurrent after a bright conditioning flash that bleached $10-20 \%$ of rhodopsin in the retina. The probe flash stimulated $\sim 2 \times 10^{5}$ photoisomerisations per rod. WT, Wild type.

Effect of the G38D mutation on the sensitivity of scotopic vision

Because Nougaret patients have difficulty functioning under low light conditions (Sandberg, 1998), we evaluated the thresholds for scotopic vision behaviorally using a water maze (Sampath et al., 2005). The back walls of five chambers of the maze were white, whereas the sixth wall, associated with a ramp and platform, was black. Mice were trained to find the black wall and the ramp. We evaluated the average time required to find the platform (relative to the average time in complete darkness) over a range of light intensities. The visual thresholds were estimated as the light intensity at which the average time to find the platform was $50 \%$ of that in darkness. The analysis showed that the visual threshold for $\mathrm{G} 38 \mathrm{D} / \mathrm{T} \alpha^{+/-}$mice is higher than the thresholds for either $\mathrm{T} \alpha^{+/+}$ or T $\alpha^{+/-}$mice (Fig. 9). G38D/T $\alpha^{-/-}$mice displayed markedly reduced visual sensitivity with a threshold similar to that of $\mathrm{T} \alpha^{-1-}$ mice, which use only cones for vision. These results are consistent with the decrease in sensitivity observed in the singlecell recordings and the lack of G38D-driven PDE6 activity observed in vitro.

\section{Discussion}

The G38D mutation in T $\alpha$ is important from the perspectives of both retinal disease and G-protein signaling in general. Mutations in $\mathrm{G} \alpha$ subunits that cause abnormal signaling have been linked to a variety of inherited diseases (Farfel et al., 1999). The two principal mechanisms of G-protein-linked diseases are excessive (constitutive) and reduced signal transduction. GTPasedeficient $\mathrm{G} \alpha$ mutants represent the best-characterized mechanism of excessive signaling caused by delayed signal termination (Landis et al., 1989; Masters et al., 1990; Weinstein et al., 1991). Decreased signaling typically results from the reduced ability of mutant G-proteins to interact with and be activated by cognate receptors (Farfel et al., 1999). Although no specific disease with subnormal G-protein signaling has been found to result from the reduced ability of the mutant G-proteins to activate their effectors, this is clearly a plausible mechanism.

The mechanism by which the G38D mutation in transducin causes impaired rod function in Nougaret patients has been unclear but has been expected to arise from excessive signaling, based on analogous mutations in related proteins. The G38D counterpart mutation in $\mathrm{p} 21$ ras, G12V, inhibits the intrinsic GTPase activity and the stimulation by GAPs (Trahey and McCormick, 1987; Lowy and Willumsen, 1993). Likewise, the Gi $\alpha_{1} \mathrm{G} 42 \mathrm{~V}$ mutant has a 30 -fold lower $k_{\text {cat }}$ for GTP hydrolysis compared with the wild-type Gi $\alpha_{1}$, and it is insensitive to RGS proteins (Raw et al., 1997). Provided that the substitution of a Gly residue in $\mathrm{G} \alpha$ subunits does not interfere with their ability to interact with effectors, these $\mathrm{G} \alpha$ mutants are expected to produce excessive signaling. However, in addition to a moderate GTPase deficiency, analysis of the G38D substitution in the context of chimeric T $\alpha^{*}$ in vitro indicated marked impairment of the mutant capacity to activate PDE6, suggesting that inadequate effector activation might be an underlying mechanism in Nougaret night blindness (Muradov and Artemyev, 2000).

Transgenic mouse lines expressing G38D in the $\mathrm{T} \alpha^{+/-}$and $\mathrm{T} \alpha^{-1-}$ backgrounds were generated to elucidate the Nougaret mechanism in vivo. Immunohistochemical analysis showed correct localization of G38D to the OS in dark-adapted transgenic rods and a normal translocation of the mutant to the IS in response to light. Interestingly, this phenotype contrasts with that of a "true" constitutively active GTPase-deficient Q200L mutant of T $\alpha$. The severe impairment of the Q200L GTPase activity coincides with an extremely delayed and incomplete translocation of the mutant from the rod IS to the OS during dark adaptation (Kerov et al., 2005). Furthermore, Q200L causes dramatic downregulation of the PDE6 catalytic subunits in transgenic rods (Raport et al., 1994; Kerov et al., 2005), whereas the PDE6 levels in G38D transgenic rods are normal.

Biochemical analysis of G38D using ROSs isolated from $\mathrm{G} 38 \mathrm{D} / \mathrm{T} \alpha^{-1-}$ mice indicated both reduced GTPase activity and impaired effector activation by the mutant. The physiological phenotypes of G38D mice supported the mutant deficiencies 

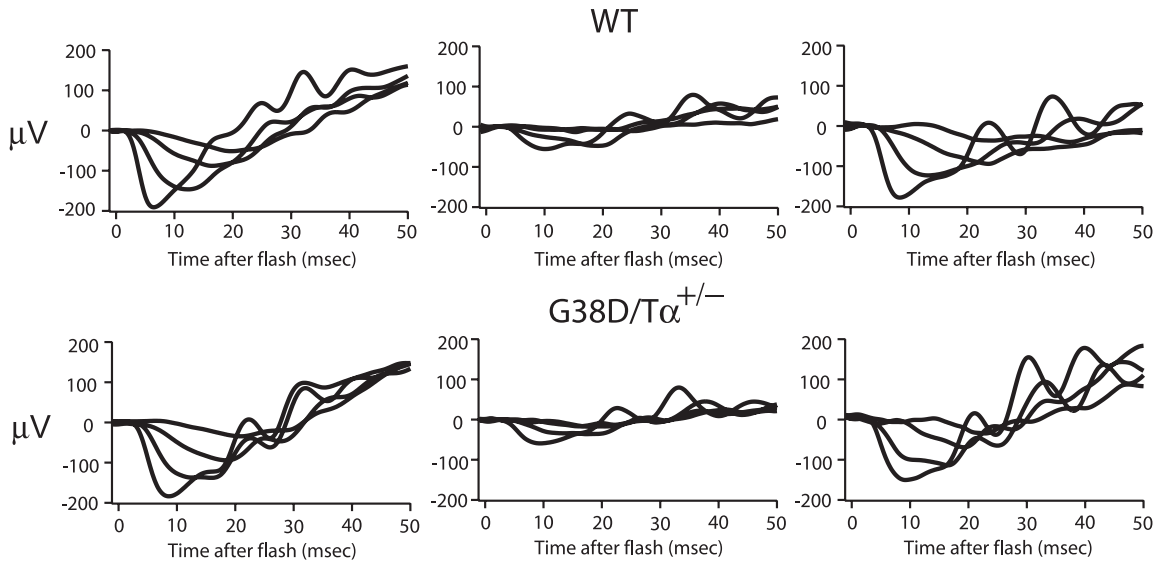

Figure 8. Dark adaptation after continuous light exposure. ERG a-wave recordings are shown. Left, Mice were dark adapted overnight, and ERGs were recorded. Middle, Mice were dark adapted overnight, exposed to 200 lux white light for 50 min, and dark adapted again for $35 \mathrm{~min}$. The mice were not anesthetized until $5 \mathrm{~min}$ before the ERGs were recorded. Right, Mice were dark adapted overnight, exposed to 200 lux white light for $50 \mathrm{~min}$, and dark adapted again for $60 \mathrm{~min}$. The mice were not anesthetized until 5 min before the ERGs were recorded. Top panels, Wild-type mice; bottom panels, G38D/T $\alpha^{+/-}$mice. Flashes were estimated to produce between $4 \times 10^{2}$ (dimmest) to $2 \times 10^{5}$ (brightest) photoisomerisations per rod.

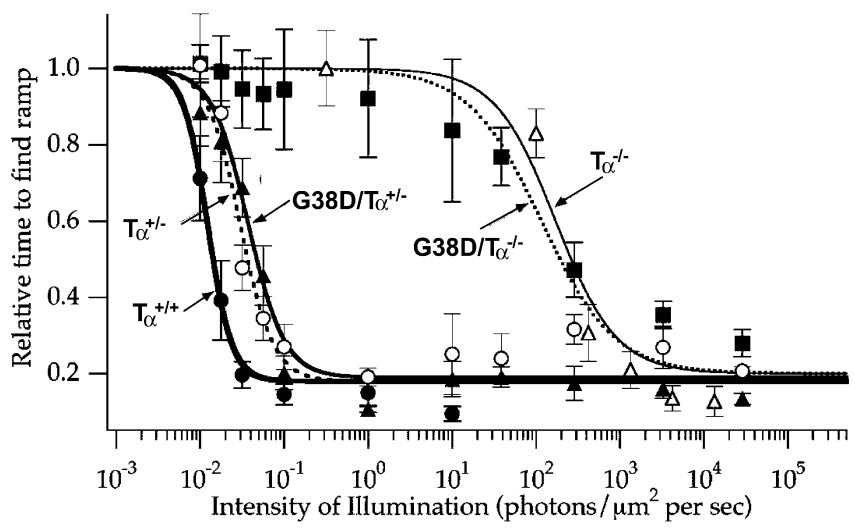

Figure 9. Visual sensitivities of control and transgenic mice. Visual sensitivities of $\mathrm{T} \alpha^{+/+}$, $\mathrm{T} \alpha^{+1-}, \mathrm{T} \alpha^{-1-}, \mathrm{G} 38 \mathrm{D} / \mathrm{T} \alpha^{+1-}$, and G38D/T $\alpha^{-1-}$ mice ( $n>4$ for each genotype), as measured using a vision-dependent behavior, are shown. Mice were trained to find a black wall in a water maze where one wall was black and five walls were white. They were then tested for their ability to find the black wall at various levels of illumination.

identified in vitro because both activation and recovery of photoresponses were affected in transgenic rods. Flash responses from individual $\mathrm{G} 38 \mathrm{D} / \mathrm{T} \alpha^{-1-}$ rods displayed an $\sim 40$-fold reduction in sensitivity, and the rate of rise of the light-activated PDE6 activity was much smaller than in wild-type rods. In addition, the PDE6 activation defect of G38D led to a dramatic loss of sensitivity of rod-mediated vision in $\mathrm{G} 38 \mathrm{D} / \mathrm{T} \alpha^{-1-}$ mice as assessed by vision-dependent behavior using a water maze. This reduced sensitivity may reflect both the inefficient activation of PDE6 by the mutant protein as well as the reduced overall expression level of $\mathrm{T} \alpha$. The fact that G38D protein can activate PDE6 in vivo but not in vitro is likely explained by the fact that a higher concentration of the activated mutant is produced in intact rods. For example, flashes producing the half-maximal responses in $\mathrm{G} 38 \mathrm{D} / \mathrm{T} \alpha^{-/-}$ rods (2200 photons $\mu \mathrm{m}^{-2}$ ) elicit one or more photoisomerizations per disc and cause activation of a sizable fraction of the total transducin pool (Lyubarsky and Pugh, 1996). Under these conditions, the concentration of activated G38D in G38D/T $\alpha^{-1-}$ rods would be much higher than under the PDE assay conditions in vitro.
In addition to inefficient activation of PDE6, G38D mutant rods showed light responses that recovered much more slowly than those of control mice. The slow component of the recovery phase was apparent in the responses of single rods to bright flashes from G38D/T $\alpha^{+/-}$mice and at all flash strengths in $\mathrm{G} 38 \mathrm{D} / \mathrm{T} \alpha^{-1-}$ rods. The ERG responses of $\mathrm{G} 38 \mathrm{D} / \mathrm{T} \alpha^{+/-}$mice also demonstrated slowed recovery and delayed dark adaptation after intense flashes. The slowed recovery is likely attributable to the reduced intrinsic GTPase activity of G38D combined with its weak stimulation by the GAP complex RGS9/G $\beta_{5} / \mathrm{R} 9 A P$ (He et al., 1998; Makino et al., 1999; Chen et al., 2000; Muradov and Artemyev, 2000; $\mathrm{Hu}$ and Wensel, 2002). Moreover, because G38D has reduced affinity for $\mathrm{P} \gamma, \mathrm{P} \gamma$ is likely to be less effective at increasing the affinity of the RGS9 complex for the mutated T $\alpha$ (Martemyanov et al., 2003), thereby further diminishing the GAP

activity.

Modeling of the T $\alpha$ G38D mutant using the crystal structure of the Gi $\alpha_{1} \mathrm{G} 42 \mathrm{~V}$ mutant (Raw et al., 1997) offers a solid structural rationale for both the deactivation and effector defects of the Nougaret mutant. The side chains of Asp and Val have similar size, and the G38D mutation in T $\alpha$ is likely to lead to similar structural consequences as $\mathrm{G} 42 \mathrm{~V}$ in $\mathrm{Gi} \alpha_{1}$. The structure of the $\mathrm{T} \alpha / \mathrm{P} \gamma /$ RGS9 complex shows that $\mathrm{G} \ln 200$ of $\mathrm{T} \alpha$, a key residue for GTP hydrolysis, interacts with the critical RGS9 GAP residue Asn364, whereas Ser202 of T $\alpha$ makes contacts with Asn364 and Trp362 of RGS9 (Slep et al., 2001). The model of G38D suggests the Asp side chain forces the peptide planes of T $\alpha$ residues 199202 to rotate, thereby pushing Gln200 out of the active site for GTP hydrolysis and disrupting the critical interaction site with RGS9 (supplemental Fig. $1 \mathrm{~A}$, available at www.jneurosci.org as supplemental material). Concurrent rotation of the side chain of T $\alpha$ Arg201 would disrupt its contacts with the $\mathrm{P} \gamma$ residues Val66 and Ile67 (Slep et al., 2001) (supplemental Fig. 1 B, available at www.jneurosci.org as supplemental material). Also, Arg201, through its contacts with Glu232 and Glu241 of T $\alpha$, is essential to the linkage between the switch II and switch III/ $\alpha 3$-helix regions. This linkage is critical for the interaction with $\mathrm{P} \gamma$, and its disruption in the Nougaret mutant may contribute to the ineffective activation of PDE6 (Natochin et al., 1998; Slep et al., 2001).

Our experiments clearly suggest that the elevated darkadapted thresholds in Nougaret patients heterozygous for the mutation do not arise from constitutive activity or a dominantnegative function of the G38D mutant, because the maximal response amplitudes were unaffected in $\mathrm{G} 38 \mathrm{D}$-expressing rods and because the sensitivity of $\mathrm{G} 38 \mathrm{D} / \mathrm{T} \alpha^{+/-}$rods was similar to that of $\mathrm{T} \alpha^{+/-}$rods, which have comparable T $\alpha$ levels. It is striking that the visual thresholds in Nougaret patients are elevated 100-fold (Sandberg et al., 1998), whereas the loss of sensitivity in G38D/ $\mathrm{T} \alpha^{+/-}$rods was considerably less. The nature of the phenotypic difference between humans and mice is not clear. However, impaired rod signaling caused by the mutation may have a greater impact for human vision because of potential differences in processing rod signals in primate and mouse retina (Field and Rieke, 2002; Field et al., 2005). Although mouse models are widely accepted as excellent tools to examine molecular consequences of 
disease-causing mutations in vivo, our study also provides an illustration of limitations of mouse models for the full understanding of human visual disease mechanisms.

\section{References}

Arshavsky VY, Lamb TD, Pugh Jr EN (2002) G proteins and phototransduction. Annu Rev Physiol 264:153-187.

Artemyev NO (1997) Binding of transducin to light-activated rhodopsin prevents transducin interaction with the rod cGMP-phosphodiesterase $\gamma$-subunit. Biochemistry 36:4188-4193.

Barbacid M (1987) Ras genes. Annu Rev Biochem 56:779-828.

Bayer AU, Mittag T, Cook P, Brodie SE, Podos SM, Maag KP (1999) Comparisons of the amplitude size and the reproducibility of three different electrodes to record the corneal flash electroretinogram in rodents. Doc Ophthalmol 98:233-246.

Brann MR, Cohen LV (1987) Diurnal expression of transducin mRNA and translocation of transducin in rods of rat retina. Science 235:585-587.

Burns ME, Baylor DA (2001) Activation, deactivation, and adaptation in vertebrate photoreceptor cells. Annu Rev Neurosci 24:779-805.

Calvert PD, Krasnoperova NV, Lyubarsky AL, Isayama T, Nicolo M, Kosaras B, Wong G, Gannon KS, Margolskee RF, Sidman RL, Pugh Jr EN, Makino CL, Lem J (2000) Phototransduction in transgenic mice after targeted deletion of the rod transducin $\alpha$-subunit. Proc Natl Acad Sci USA 97:13913-13918.

Chen CK, Burns ME, He W, Wensel TG, Baylor DA, Simon MI (2000) Slowed recovery of rod photoresponse in mice lacking the GTPase accelerating protein RGS9-1. Nature 403:557-560.

Danciger M, Matthes MT, Yasamura D, Akhmedov NB, Rickabaugh T, Gentleman S, Redmond TM, La Vail MM, Farber DB (2000) A QTL on distal chromosome 3 that influences the severity of light-induced damage to mouse photoreceptors. Mamm Genome 11:422-427.

Dryja TP (2000) Molecular genetics of Oguchi disease, fundus albipunctatus, and other forms of stationary night blindness: LVII Edward Jackson Memorial Lecture. Am J Ophthalmol 130:547-563.

Dryja TP, Hahn LB, Reboul T, Arnaud B (1996) Missense mutation in the gene encoding the alpha subunit of rod transducin in the Nougaret form of congenital stationary night blindness. Nat Genet 13:358-360.

Farfel Z, Bourne HR, Iiri T (1999) The expanding spectrum of G protein diseases. N Engl J Med 340:1012-1020.

Field GD, Rieke F (2002) Nonlinear signal transfer from mouse rods to bipolar cells and implications for visual sensitivity. Neuron 34:773-785.

Field GD, Sampath AP, Rieke F (2005) Retinal processing near absolute threshold: from behavior to mechanism. Annu Rev Physiol 7:491-514.

Hayes JM, Balkema GW (1993) Elevated dark-adapted thresholds in hypopigmented mice measured with a water maze screening apparatus. Behav Genet 23:395-403.

He W, Cowan CW, Wensel TG (1998) RGS9, a GTPase accelerator for phototransduction. Neuron 20:95-102.

Hu G, Wensel TG (2002) R9AP, a membrane anchor for the photoreceptor GTPase accelerating protein, RGS9-1. Proc Natl Acad Sci USA 99: 9755-9760.

Kennedy MJ, Lee KA, Niemi GA, Craven KB, Garwin GG, Saari JC, Hurley JB (2001) Multiple phosphorylation at rhodopsin and the in vivo chemistry underlying rod photoreceptor dark adaptation. Neuron 31:87-101.

Kerov V, Chen D, Moussaif M, Chen YJ, Chen CK, Artemyev NO (2005) Transducin activation state controls its light-dependent translocation in rod photoreceptors. J Biol Chem 280:41069-41076.

Krispel CM, Chen CK, Simon MI, Burns ME (2003) Novel form of adaptation in mouse retinal rods speeds recovery of phototransduction. J Gen Physiol 122:703-712.

Landis CA, Masters SB, Spada A, Pace AM, Bourne HR, Vallar L (1989) GTPase inhibiting mutations activate the alpha chain of Gs and stimulate adenylyl cyclase in human pituitary tumours. Nature 340:692-696.

Lem J, Fain GL (2004) Constitutive opsin signaling: night blindness or retinal degeneration? Trends Mol Med 10:150-157.

Lem J, Applebury ML, Falk JD, Flannery JG, Simon MI (1991) Tissue- specific and developmental regulation of rod opsin chimeric genes in transgenic mice. Neuron 6:201-210.

Lowy DR, Willumsen BM (1993) Function and regulation of ras. Annu Rev Biochem 62:851-891.

Lyubarsky AL, Pugh Jr EN (1996) Recovery phase of the murine rod photoresponse reconstructed from electroretinographic recordings. J Neurosci 16:563-571.

Makino ER, Handy JW, Li T, Arshavsky VY (1999) The GTPase activating factor for transducin in rod photoreceptors is the complex between RGS9 and type $5 \mathrm{G}$ protein $\beta$ subunit. Proc Natl Acad Sci USA 96:1947-1952.

Martemyanov KA, Hopp JA, Arshavsky VY (2003) Specificity of G proteinRGS protein recognition is regulated by affinity adapters. Neuron $38: 857-862$.

Masters SB, Landis CA, Bourne HR (1990) GTPase-inhibiting mutations in the $\alpha$ subunit of Gs. Adv Second Messenger Phosphoprotein Res 24:70-75.

Medina R, Grishina G, Meloni EG, Muth TR, Berlot CH (1996) Localization of the effector-specifying regions of Gi2 $\alpha$ and Gq $\alpha$. J Biol Chem 271:24720-24727.

Muradov KG, Artemyev NO (2000) Loss of the effector function in a transducin- $\alpha$ mutant associated with Nougaret night blindness. J Biol Chem 275:6969-6974.

Natochin M, Granovsky AE, Artemyev NO (1998) Identification of effector residues on photoreceptor G-protein, transducin. J Biol Chem 273:21808-21815.

Philp NJ, Chang W, Long K (1987) Light-stimulated protein movement in rod photoreceptor cells of the rat retina. FEBS Lett 225:127-132.

Pugh Jr EN, Lamb TD (1993) Amplification and kinetics of the activation steps in phototransduction. Biochim Biophys Acta 1141:111-1149.

Raport CJ, Dere B, Hurley JB (1989) Characterization of the mouse rod transducin $\alpha$ subunit gene. J Biol Chem 264:7122-7128.

Raport CJ, Lem J, Makino C, Chen CK, Fitch CL, Hobson A, Baylor D, Simon MI, Hurley JB (1994) Downregulation of cGMP phosphodiesterase induced by expression of GTPase-deficient cone transducin in mouse rod photoreceptors. Invest Ophthalmol Vis Sci 35:2932-2947.

Raw AS, Coleman DE, Gilman AG, Sprang SR (1997) Structural and biochemical characterization of the GTP $\gamma \mathrm{S}-$, GDP·Pi-, and GDP-bound forms of a GTPase-deficient $\mathrm{Gly}^{42} \rightarrow$ Val mutant of $\mathrm{G}_{\mathrm{i} \alpha 1}$. Biochemistry 36:15660-15669.

Sampath AP, Strissel KJ, Elias R, Arshavsky VY, McGinnis JF, Chen J, Kawamura S, Rieke F, Hurley JB (2005) Recoverin improves rodmediated vision by enhancing signal transmission in the mouse retina. Neuron 46:413-420.

Sandberg MA, Pawlyk B, Dan J, Arnaud B, Dryja TP, Berson EL (1998) Rod and cone function in the Nougaret form of stationary night blindness. Arch Ophthalmol 116:867-872.

Slep KC, Kercher MA, He W, Cowan CW, Wensel TG, Sigler PB (2001) Structural determinants for regulation of phosphodiesterase by a $\mathrm{G}$ protein at 2.0 A. Nature 409:1071-1077.

Sokolov M, Lyubarsky AL, Strissel KJ, Savchenko AB, Govardovskii VI, Pugh Jr EN , Arshavsky VY (2002) Massive light-driven translocation of transducin between the two major compartments of rod cells: a novel mechanism of light adaptation. Neuron 34:95-106.

Trahey M, McCormick F (1987) A cytoplasmic protein stimulates normal $\mathrm{N}$-ras p21 GTPase, but does not affect oncogenic mutants. Science 238:542-545.

Tsang SH, Burns ME, Calvert PD, Gouras P, Baylor DA, Goff SP, Arshavsky VY (1998) Role for the target enzyme in deactivation of photoreceptor G protein in vivo. Science 282:117-121.

Weinstein LS, Shenker A, Gejman PV, Merino MJ, Friedman E, Spiegel AM (1991) Activating mutations of the stimulatory G protein in the McCune-Albright syndrome. N Engl J Med 325:1688-1695.

Whelan JP, McGinnis JF (1988) Light-dependent subcellular movement of photoreceptor proteins. J Neurosci Res 20:263-270.

Wilson PT, Bourne HR (1995) Fatty acylation of $\alpha z$. Effects of palmitoylation and myristoylation on $\alpha \mathrm{z}$ signaling. J Biol Chem 270:9667-9675.

Woodford BJ, Chen J, Simon MI (1994) Expression of rhodopsin promoter transgene product in both rods and cones. Exp Eye Res 58:631-635. 